\title{
O PROBLEMA DA PARTICIPACÃO DOS CATÓLICOS NO PODER POLÍTICO EM LOCKE
}

\author{
Mykael Morais Viana ${ }^{1}$
}

RESUMO: O presente trabalho tem por objetivo analisar os posicionamentos do filosofo inglês John Locke com relação à participação dos Papistas, ou Católicos, no poder político. Locke buscou estabelecer diretrizes para a ação do Estado em sua relação com a religião. Para ele, a tolerância religiosa é um elemento fundamental para a construção de uma boa sociedade e ela só poderá se estabelecer quando Estado e religião forem esferas completamente distintas. Porém, existem elementos na religião que podem ser nocivos ao bom andamento da Sociedade. Um exemplo de elemento nocivo dentro da religião é quando seus membros atribuem a si mesmos a soberania política fundamentada na infalibilidade de sua crença. Além disso, alguns religiosos afirmam que o líder da sua religião tem poder político superior ao poder público. Para Locke, quando isso acontece, a soberania do Estado está em risco, pois os cidadãos recusam-se a submeter-se ao poder público, argumentando que a única autoridade possível é a religiosa. É devido a isso que Locke enxerga no Catolicismo a fonte de problemas para a organização política. Apresentaremos aqui as principais razões de Locke para atacar o Papismo tendo como foco suas obras políticas. 
PALAVRAS-CHAVE: Política, Catolicismo, Tolerância, Infalibilidade, Religião.

ABSTRACT: This study aims to analyze the positions of the English philosopher John Locke respecting the participation of Papists, or Catholics, in political power. Locke sought to establish guidelines for state action in its relation with religion. For him, religious tolerance is a key element for building a good society and it can only be established when state and religion are completely different spheres. However, there are elements in religion that can be harmful to the smooth running of the community. A harmful element of example within the religion is when its members give themselves political sovereignty based on the infallibility of their belief. In addition, some religious claim that the leader of his religion has superior political power to the government. For Locke, when that happens, the state's sovereignty is at risk because the citizens refuse to submit to the government, arguing that the only possible authority is religious. It is due to this that Locke sees in Catholicism a source of problems for the political organization. We present here the main reasons for Locke to attack Papism focusing their political works.

KEYWORDS: Politics, Catholicism, Tolerance, Infallibility, Religion. 


\section{CONSIDERAÇÕES INICIAIS}

No contexto dos conflitos e revoluções da Inglaterra do século XVII, o filósofo John Locke (1642-1704) propõe uma solução política para as divergências entre as igrejas que tanto ocasionavam violência no seio da comunidade. Para Locke, a instituição de uma lei de tolerância, baseada na separação entre Estado e religião era a melhor solução para por fim aos conflitos. Porém, ao estabelecer os limites da tolerância, Locke exclui os Católicos, à época chamados pejorativamente de Papistas ${ }^{2}$. O presente trabalho tem por objetivo analisar os argumentos usados por Locke para defender que a existência de Papistas na sociedade civil põe em perigo a soberania do Estado. Para atingirmos nosso objetivo, partiremos de uma definição geral da ideia de Soberania em Locke, para então passarmos a analisar os fundamentos da argumentação contra os papistas.

Os argumentos de Locke que analisaremos partem de dois registros: um de ordem política, onde ele defende que o cidadão fiel a determinada religião, que reconhece seu líder eclesiástico não só como um guia espiritual, mas também um líder político, não deve ser tolerado na sociedade; outro de ordem epistemológica, onde o fiel atribui a si mesmo e a outros que compartilham de sua fé um estatuto de infalibilidade, o que vai contra as teses empiristas de Locke, e também têm desdobramentos nas questões políticas, pois 
a possibilidade de uma infalibilidade daria certos direitos a uns e não a outros, o que, para Locke, representa perigo de dissolução da sociedade.

\section{A SOBERANIA DO ESTADO E A SOBERANIA DAS LEIS}

Primeiramente, é preciso definir o que seja Soberania do Estado em Locke. Como se sabe, Locke é um filosofo contratualista. Ele defende que a sociedade política foi constituída como saída para os inconvenientes do estado de natureza. Nesse estado pré-social, o homem possuía total liberdade de ação e direito sobre as coisas que produzisse na natureza. A esses direitos Locke dá o nome de propriedade. $\mathrm{O}$ inconveniente desse estado se dava quando um indivíduo violava a propriedade do outro. Não havia no estado de natureza ninguém que pudesse ser o juiz entre as partes antagônicas. A punição para a agressão era então definida e aplicada pela própria vitima. Para Locke, o problema disso era que o critério de justiça partia de cada um e a pena só era aplicada se a vítima tivesse força o suficiente para submeter o agressor. Esses inconvenientes fizeram com que os indivíduos tivessem o desejo de unir-se em grupos maiores e definissem, através de um acordo, quais seriam as leis e as normas a serem seguidas por todos os membros. Ele afirma: "Parece-me que o Estado é uma sociedade de 
homens constituída unicamente com o fim de conservar e promover os seus bens civis. É dever do magistrado civil assegurar a todo o povo e a cada súdito em particular, mediante leis impostas igualmente a todos, a boa conservação e a posse de todas as coisas que se relacionam com essa vida." (LOCKE, 1965, p.92). A sociedade civil é, portanto, uma reunião de homens livres que abrem mão do uso da força para que esta esteja reunida na figura do Estado. A força do Estado reside na soma da força de todos os cidadãos e só deve ser usada com o intuito de preservar o direito à propriedade. $\mathrm{O}$ magistrado ${ }^{3}$ não tem poder enquanto cidadão comum. Seu poder deriva do poder de todos e não deve ser usado para promover interesses particulares, mas sim os interesses da comunidade.

O Estado torna-se então soberano, pois cabe exclusivamente a ele o poder de julgar e condenar, aplicando penas àqueles que romperem o pacto, infringindo danos à propriedade de qualquer cidadão. Porém, soberania aqui não se confunde com absolutismo. $O$ Estado lockeano não é absoluto, ou seja, os critérios de justiça que orientam o governo são aqueles aceitos por toda a sociedade e não impostos pelos que estão no poder. O pacto e a solidificação do Estado não tiram dos homens direitos que eles tinham antes. Abre-se mão apenas do direito de execução da lei. Porém, a liberdade e as posses continuam sendo direitos inalienáveis. A instituição de leis positivas também impõe 
que todos passem a submeter-se a uma legislatura comum, definida em consenso pela própria comunidade civil. Locke afirma:

Pois a lei, em sua verdadeira concepção, não é tanto uma limitação quanto a direção de um agente livre e inteligente rumo a seu interesse adequado, e não prescreve além daquilo que é para o bem geral de todos quantos lhe estão sujeitos. Se estes pudessem sem mais felizes sem ela, a lei desapareceria por si mesma como coisa inútil; e mal mereceria o nome de restrição a sebe que nos protegesse apenas de pântanos e precipícios. De modo que, por mais que possa sem mal interpretado, o fim da lei não é abolir ou restringir, mas conservar e ampliar a liberdade, pois, em todos os estados de seres criados capazes de leis, onde não há lei, não há liberdade. (LOCKE, 2005, p.433)

O objetivo da lei é assegurar a liberdade e todos aqueles que desejem ferir a liberdade ferem a lei, e consequentemente se colocam contra toda a sociedade. Desse modo, a lei não representa uma coerção, mas sim o desejo de todos aqueles que se reuniram em torno de interesses comuns. $\hat{E}$ importante que as leis sejam soberanas, ou seja, que não seja facultado a ninguém o direito de seguir ou não as leis. Uma lei só deve deixar de ser 
seguida quando deixa de ser lei, mas enquanto ela vigora, todos estão obrigados a cumpri-la, pois foram os próprios cidadãos que assim o quiseram ${ }^{4}$.

O Estado, representado pelos magistrados, não está excluído de obedecer às leis positivas nem à lei natural. O único propósito do Estado é salvaguardar a propriedade dos cidadãos, que são sua vida, a liberdade e seus bens. Para Locke, não cabe nas atribuições do Estado legislar sobre outras questões que dizem respeito à esfera privada dos indivíduos. Ou seja, Locke defende que qualquer aspecto da vida privada das pessoas que não interfira na propriedade dos outros cidadãos ou afete o Estado, não deve ser alvo de sanções, nem regulado através de leis. Esse é um ponto central no pensamento político de Locke, pois ele defende que as práticas religiosas são ações livres que não interferem no andamento da sociedade. Como dito antes, a soberania das leis não impede que as pessoas exerçam sua liberdade, desde que essa não entre em conflito com os interesses sociais. Existe, portanto um limite para o poder público. A isso Locke chama coisas indiferentes. Tudo aquilo que não interfira no bom andamento da sociedade é considerado indiferente e não deve sofrer sanções ou ser alvo de leis por parte do magistrado. A escolha individual por determinada religião é algo que Locke caracteriza por indiferente, ou seja, não faz diferença para o Estado o tipo de prática religiosa ou opinião especulativa que alguém escolha abraçar. 
Se, portanto, a religião não deve ser alvo de sanções do Estado caso não ameace a estrutura social, quais são os motivos que levam Locke a negar o direito de tolerância aos Papistas? O primeiro argumento de Locke, de ordem política, pode ser encontrado na seguinte passagem da Carta acerca da Tolerância:

A igreja em que cada um passa ipso facto para o serviço e a obediência de outro príncipe não pode ter o direito de ser tolerada pelo magistrado. Se tal admitisse, o magistrado introduziria, no interior das suas fronteiras e cidades, uma jurisdição estrangeira; e permitiria que entre os seus cidadãos se alistassem soldados para combater o Estado. Para esse mal, a distinção inútil e capciosa entre Corte e a igreja não trás remédio algum, porque tanto uma como a outra estão igualmente sujeitas à soberania absoluta do mesmo homem, que pode aconselhar aos membros da sua igreja tudo o que lhe agradar, tudo o que é espiritual ou se ordena ao espiritual e mais ainda, o pode impor sob pena do fogo eterno. (LOCKE, 1965, p.117-118).

Dois são os pontos a serem observados nessa passagem da Carta. O primeiro é o argumento de Locke de que o líder político não deve ser confundido com o líder religioso, ou seja, ambos os poderes não devem concentrar- 
se na mesma pessoa, isso porque um líder que é político e religioso ao mesmo tempo gera sentimentos negativos dos cidadãos que não seguem essa religião. Além do fato de que tal líder é uma pessoa como qualquer outra e pode, devido à sua preferência religiosa, usar o poder público para atacar os fieis de outras religiões. Isso não significa que o magistrado não possa ter opção religiosa. Para Locke está claro que o magistrado enquanto cidadão é igual a todos os outros e tem os mesmos direitos. Suas atribuições não se confundem e ele não pode usar a máquina pública para promover sua fé o que não exclui a possibilidade de promovê-la através dos modos comuns permitidos a todos os cidadãos.

O segundo ponto está no centro de sua argumentação contra os Papistas. Para Locke, o cidadão que segue determinada religião, cujo líder exerce algum poder político sobre ele, não deve ser tolerado. Em outras palavras, não deve ser permitido ao cidadão morar em um país que tem leis e ainda assim, não se submeter a elas usando o argumento de que só deve obedecer ao seu líder religioso. Se o líder de uma religião é também um líder político então aqueles que o seguem não são apenas fieis, mas são também súditos de um príncipe. Ora, não é por ser religioso que um príncipe deixa de ser um líder político. O que há aqui é uma confusão entre conselhos religiosos e decretos estatais. Locke afirma: 
O legislativo é não apenas o poder supremo da sociedade política, como também é sagrado e inalterável nas mãos em que a comunidade o tenha antes depositado; tampouco pode edito algum de quem quer que seja, seja de que forma for concebido ou por que poder apoiado, ter força e obrigação de lei se não for sancionado pelo legislativo escolhido e nomeado pelo público. Pois, não fosse assim, não teria a lei o que é absolutamente necessário à lei, o consentimento da sociedade, sobra a qual ninguém poder ter o poder de elaborar leis salvo por seu próprio consentimento, e pela autoridade dela recebida. (LOCKE, 2005, p.502-503)

Se o poder eclesiástico e o poder político se confundem em um só homem, da mesma forma a igreja se confunde com o Estado e todos aqueles que seguem esse líder são, ao mesmo tempo, fieis de sua igreja e súditos do seu Estado. Para Locke, permitir que o cidadão seguidor dessa religião estabeleça-se em outro país constitui uma perigosa ameaça à soberania do Estado. Esse cidadão desejará ter os direitos provenientes do seu novo país, porém, sem jurar obediência às suas leis. Não deve ser permitido a nenhum cidadão um tratamento diferenciado por conta de sua opção religiosa. Se o cidadão afirma que não obedece às leis do país logo, não deve ser permitido a 
ele estabelecer-se nesse país, independente da sua motivação religiosa.

O problema do Papismo é que ele exige do fiel um juramento de fidelidade a seu poder, de forma incondicional. Todo aquele que se diz católico vê no líder religioso, o Papa, uma figura de poder, não só espiritual, mas também político. Se o líder político se confunde com o líder religioso e suas leis são aceitas e apoiadas pelo povo, não há problema algum na visão de Locke. O que ocasiona problemas é quando um Papista vive em um país que não reconhece a figura do Papa como líder político, pois tem seus próprios líderes e suas leis. Ora, se o cidadão, seja ele Papista ou não, goza dos direitos e recursos de um determinado país, então ele está obrigado a seguir as leis daquele país. Locke reitera: "Não pode um juramento a um poder externo qualquer ou a algum poder interno subordinado dispensar nenhum membro da sociedade de sua obediência ao legislativo". (LOCKE, 2005, p.504). Permitir a alguém não seguir a lei é abrir uma perigosa exceção na soberania do Estado. Como vimos, todos os membros estão obrigados a seguir a lei, pois de comum acordo reconhecem a legitimidade de suas legislações. Se um cidadão, por ser Papista e, portanto, fiel ao Papa, não reconhece a autoridade política de um país, então ele não pode gozar dos direitos e recursos daquele país, não sendo, portanto, incluído na lei de tolerância. 
A teoria de Locke tem uma intenção eminentemente prática. A solução proposta por ele está totalmente relacionada com os problemas políticos de sua época. Contudo, isso não limita o autor a ser um escritor datado e pouco relevante para a compreensão teórica mais ampla dos problemas político-filosóficos. Pelo contrário, compreender Locke como um autor que pensa a política na prática nos permite melhor definir a extensão e os limites do seu pensamento. Laslett afirma:

Com seu instinto contrario ao pensamento sintético, portanto, Locke não estava submetido a nenhuma necessidade lógica de considerar as conclusões autoritárias do sistema hobbesiano, e já demonstramos que não havia nenhum motivo político possível para que o fizesse. Os Dois Tratados diferiam de modo bastante considerável do Leviatã em sua forma de argumentação, tanto por essas razões, como em Razão de Filmer e da atitude lockeana que contrastavam tanto com a atitude de Hobbes. Continham exatamente o ingrediente que faltava no Leviatã: prática política. (LASLETT, 2005, p.132).

Laslett ressalta a importância da compreensão histórica para o esclarecimento de certos aspectos do pensamento desse autor. É preciso notar o paralelo 
permanente entre a teoria que está relacionada com uma reflexão filosófica por excelência, e a prática, que abrange o autor enquanto teórico, mas também enquanto cidadão do seu tempo. $\mathrm{Na}$ época de Locke a Inglaterra vivia um momento delicado no que dizia respeito à religião. A reforma protestante havia efetuado profundas mudanças na forma como as diversas nações europeias lidavam com a Igreja Católica. Essa por sua vez ainda era dona de grande poder econômico e político e, portanto, grande influência entre os governos. Locke, que era protestante, e buscava através de sua filosofia limitar o poder da Igreja, defendia que antes de ser uma religião, a Igreja Católica constituía um país. E, dessa forma, aceitar em seu território um cidadão fiel essa Igreja era como aceitar um súdito de outro monarca. Isso deixava em risco a soberania inglesa, cuja população estava bastante dividida entre Católicos e Protestantes.

\section{A LIBERDADE DE CONSCIÊNCIA E A FALIBILIDADE DA RAZÃO}

O segundo argumento de Locke é de ordem epistemológica. Como se sabe, Locke desenvolveu uma teoria empirista do conhecimento humano. Para ele, todo conhecimento deriva da experiência, sendo captado conforme o indivíduo, que ainda na infância vai tendo 
contato e relações com o mundo. Sua concepção de como o ser na confusa política inglesa. Seu desejo de participar politicamente, através de uma reflexão sobre os fundamentos da política estão evidenciados no seu Ensaio sobre o Entendimento humano, em que defende que a capacidade racional do homem é suficiente para proporcionar-lhe uma via de escape aos inconvenientes do estado de natureza. A sociedade política, como dito anteriormente, não está fundamentada em um direito divino, mas sim em um pacto entre os homens. Esse pacto encontra seu humano adquire conhecimento é uma contraposição à teoria das ideias inatas de Descartes, e está representada na celebre expressão "tábula rasa”. Para Locke, a mente é como uma folha em branco (uma tábula), e a partir do nascimento, ela vai sendo preenchida pelas experiências, sensações, e posteriormente, reflexões. Para Locke, os seres humanos não nascem com ideias prontas, nem mesmo as mais básicas. O próprio conhecimento de Deus e também o conhecimento matemático são, assim como os outros, adquiridos ao longo das vivências e experiências com que o indivíduo se depara.

A ruptura de Locke em relação a Descartes evidencia a intenção de romper com o modelo escolástico da universidade inglesa daquela época. Para Locke, não existiam reflexões frutíferas no âmbito acadêmico que permitissem intervir fundamento na razão e é por esse 
motivo que Locke tanto preza por um aperfeiçoamento dela. Assim, Muller considera que:

Locke considera imperdoável e desprezível a atitude daquele que menospreza as vantagens do conhecimento que recebeu e se descuida em aperfeiçoá-lo. Na Carta ao Leitor chega a declarar que "não vale a pena se preocupar com o que disse ou pensa quem diz ou pensa tão somente de acordo com a orientação de outrem". E na introdução do Ensaio afirma que: "a vela que foi colocada em nós brilha o suficiente para todos os nossos propósitos". Não se faz necessária a demonstração dogmática e imoderada. Assim, Locke crê não ser preciso depender do entendimento alheio. (MULLER, 2008, p.60-61)

O que Muller evidencia é que Locke acredita que nenhum homem, seja governante, eclesiástico, ou cidadão comum, tem uma capacidade cognitiva superior aos demais. Todos os seres humanos são iguais do ponto de vista da razão e, consequentemente de direitos. Não há necessidade de impor aos homens verdades acerca de sua fé, ou de seus direitos. Para Locke, o caminho racional leva os homens a enxergar no curso ordinário da natureza, a existência de Deus, e da lei natural ${ }^{6}$. Toda e qualquer lei positiva, instituída com a fundação da sociedade, deve estar alinhada 
a essa lei natural. Como mencionado, no estado de natureza o homem já possuía propriedade, ou seja, tinha direito à sua vida, sua liberdade e à posse dos frutos de seu trabalho. Tinha também o direito de julgar e executar quem atentasse contra ele. É preciso evidenciar que esse princípio, que está no homem desde antes da sociedade, está fundamentado na razão. Para Locke, não é o advento do Estado que garante a propriedade, mas sim a lei de natureza, que é a lei da própria razão. Não há entre os homens relação de poder antes da sociedade, mas já existem direitos.

Se não há uma relação de poder natural entre os homens isso significa que são iguais cognitivamente e se não existem princípios inatos na mente, logo, nosso entendimento é falível e limitado. Adquirimos conhecimento na medida em que necessitamos deles para melhor sobreviver às dificuldades que a natureza nos impõe. $\mathrm{O}$ desenvolvimento e a educação do homem foram objetos da reflexão de Locke. Ele defende que não há conhecimento ilimitado ou indubitável. Seu intuito é atacar qualquer ideia de uma possível infalibilidade. Para ele, não existe ser humano infalível, dado que todos nós compartilhamos da mesma estrutura cognitiva. $\mathrm{O}$ argumento da infalibilidade é, não só incorreto, mas também falacioso. Aqueles que o usam buscam impor suas opiniões como sendo verdades universais, mas não usam argumentos racionais ou evidências para provar seu ponto de vista. Locke afirma: 
Os princípios que toda humanidade aceita por verdadeiros são inatos; aqueles que os homens de perfeito juízo admitem são os princípios aceitos por toda a humanidade; nós e os que têm o nosso ponto de vista, somos homens de razão; portanto, concordamos que os nossos princípios são inatos, o que é uma estupenda maneira de argumentar e um caminho mais rápido para se alcançar a infalibilidade. (LOCKE, 1973, p.155)

Fazendo um silogismo simples e usando de clara ironia, Locke demonstra que o critério de verdade daqueles que se pretendem infalíveis é autorreferente e falacioso. Defender que existem verdades inatas, que não precisam de critério para serem válidas, nada mais é do que um recurso de retórica, no qual os mesmos pensadores que afirmam a existência desse tipo de conhecimento definem quais ideias inatas existem. No fundo, os critérios de verdade são estabelecidos por eles, mas soam como se não fossem critérios e sim princípios universais. Essa argumentação demonstra claramente a intenção dos religiosos de estabelecer diretrizes para o Estado, utilizando-se do argumento de que são infalíveis. Porém, se há algum grupo na sociedade, que impõe leis aos outros sem que esses tenham delegado tal autoridade a eles, então se instala a guerra entre essas facções, dissolvendo assim o Estado. 
O contexto de insegurança e instabilidade política fez com que Locke colocasse as leis acima da autoridade política. Se mesmo a nobreza e o rei estão obrigados a seguir as leis, e essas, por sua vez, estão fundamentadas na vontade do povo, então não pode haver verdade externa à sociedade, que lhe dite as normas. Na passagem a seguir, Locke é mais enfático em sua denúncia das intenções veladas dos religiosos de se esconderem sob a capa dos argumentos religiosos para transgredir as leis do Estado. Ele diz:

Deixem que a ideia de infalibilidade seja ligada a qualquer pessoa, e essas duas constantemente unidas possuirão a mente; e então um corpo em dois lugares ao mesmo tempo será engolido incondicionalmente como se fosse uma verdade certa, por uma fé implícita, sempre que a suposta pessoa infalível ditar e exigir assentimento sem investigação. (LOCKE, 1973, p. 161).

Obviamente que o texto de Locke é dirigido contra a opinião comum que corria entre os Católicos de que o Papa era infalível. Mas também há uma crítica velada à mentalidade acadêmica da Oxford de sua época. Pois temos conhecimento de que Locke considerava infrutíferas as reflexões da universidade, que se atinham apenas à tradição. $\mathrm{O}$ argumento da autoridade, travestido de verdade universal 
estava oculto no discurso dos religiosos. Para ele, a infalibilidade só era possível se houvessem princípios inatos universais, ponto refutado no Ensaio. A crença cega nesses princípios gera nos homens o fanatismo que causa as guerras e ameaça a estrutura do Estado.

O problema de se afirmar a infalibilidade não era apenas o da crença cega. Para Locke o principal problema estava nas consequências políticas disso. A necessidade de provar a infalibilidade de um discurso mostra que há um interesse político latente. Esse discurso visa suprimir as leis, usando um meio não legítimo, pois, aquele que se diz infalível não teve sua autoridade aceita pelo povo, mas fundamenta-se em pretensos axiomas, denunciados por Locke como falácias. Na Carta, Locke afirma:

Um mal certamente mais escondido e mais perigoso para o Estado é constituído por aqueles que se arrogam, para eles e para sua seita, um privilegio particular e contrário ao direito civil. Que mais pretendem os que ensinam que não é preciso cumprir a palavra com os heréticos? Querem que lhes seja concedido o privilegio de faltar à palavra, já que todos os que não fazem parte de sua comunidade são considerados heréticos, ou podem ser considerados como tais na primeira ocasião. (LOCKE, 1965, p.117). 
As palavras "Heresia" e "Seita" são indicadas de forma tendenciosa. $\mathrm{O}$ herético é visto como um criminoso, não sendo devido a ele nada além da injustiça que ele próprio abraçou. Porém, Locke denuncia que não há na heresia nada de nocivo à sociedade. Ser herético nada mais é do que discordar em opiniões religiosas. Todos os que estão fora da minha igreja são heréticos para mim, e dessa mesma forma, o outro me vê. Não pode ser permitido a um grupo faltar com a palavra, ou não seguir as leis, apenas porque não concorda com alguém em matéria de religião. Portanto, é impossível para o Estado sustentar a equidade de suas leis quando existe em seu seio determinada religião que se arroga infalível e, portanto, no direito de transgredir qualquer lei que não tenha sido decretada por algum membro de sua igreja.

A lei de tolerância pode ser interpretada, não como um conjunto teórico ideal, mas como normas práticas, que auxiliem o magistrado a decidir melhor em um caso de conflito. Ou ainda, não só auxilie, como também evite que o poder público use as ferramentas de que dispõe para promover alguma religião específica em detrimento das outras. É obrigação não só do magistrado de seguir a lei, como também das instituições religiosas e dos indivíduos de um modo geral. Locke conclui: 
Estas pessoas e outras semelhantes, que atribuem aos fieis, aos religiosos, aos ortodoxos, isto é, a elas próprias, nas coisas civis, algum privilégio e algum poder de que o resto dos mortais não dispõe; ou que reinvidicam para si, sob pretexto de religião, certos poderes sobre os homens estranhos à sua comunidade eclesiástica, ou que dela de qualquer maneira se separaram, estas pessoas não poder ter o direito de ser toleradas pelo magistrado; nem também os que não querem ensinar que é preciso tolerar os que entram em dissidência relativamente à sua própria religião. (LOCKE, 1965, p.117)

Portanto, não só os intolerantes devem sofrer sanções, como também aqueles que não contribuam com a causa da paz em matéria de religião. Locke defende a importância das práticas religiosas na sociedade, mas pretende traçar um círculo claro entre o que são as atividades típicas da fé, e o que são os assuntos de Estado. Promover a tolerância é uma obrigação compartilhada por todos os cidadãos e não só pelo poder público.

\section{CONSIDERAÇ̃̃ES FINAIS}

Em conclusão Locke aponta argumentos baseados em sua teoria política e também epistemológica para 
demonstrar que certos posicionamentos não devem ser tolerados pelo magistrado. Dentre esses posicionamentos estão aqueles em que o cidadão admite fidelidade a um líder religioso que tem suas próprias leis civis. $\mathrm{O}$ cidadão que assim se posiciona, busca privilégios, ao passo que não cumpre seus deveres, apenas porque é súdito de outro príncipe. Porém, ele usa o argumento de que apenas segue sua religião e reivindica para si o privilegio da tolerância. Para Locke, esse privilégio só se estende à religião. Porém, se a religião, em algum momento, se confunde com o poder civil é necessário que a instituição passe a prestar contas à lei, caso contrário, a soberania estaria ameaçada, pois não se pode permitir que um grupo político não respeite as normas sociais. No fundo, a intenção de Locke é mostrar que os assuntos de religião em nada dizem respeito ao poder civil. O fiel tem o objetivo de salvar sua alma na outra vida. As práticas que ele deve adotar para agradar a divindade em nada necessitam do poder civil para serem promovidas. A diversidade de práticas em nada atrapalha o bom andamento social. É preciso que exista o espaço para essa diversidade e que se evite o conflito.

$\mathrm{O}$ segundo argumento de Locke visa derrubar a possibilidade de infalibilidade. O religioso que se diz infalível apenas tenta, através de sua autoridade, impor opiniões infundadas com o intuito de tomar para si o controle do Estado. Sendo infalível, esse líder e os fieis de 
sua religião estão justificando qualquer atitude, já que têm apenas a intenção de revelar a verdade. Aceitar isso significa aceitar quaisquer atitudes desse grupo, tais como intolerância para com os que não o seguem e desrespeito às leis que eles não concordam. Locke é um autor que preza pelo desenvolvimento racional do homem. Ele acredita que todos são capazes, através de esforços próprios, de descobrir as verdades necessárias da natureza e da criação. Impor opiniões, mesmo que de ordem abstrata, é um abuso de autoridade e uma violência contra o direito de consciência de cada um. No estado de natureza todos eram livres para professar suas crenças, e isso não se perde com a instituição de leis e a construção do Estado.

É preciso notar que as ideias de Locke do estado de natureza e também da lei de natureza levantam problemas. Estudiosos como Dunn (2003) e Laslett (2005) apontam para a existência de um inatismo em Locke. Não há como defender a existência de uma lei natural sem defender que ela já estava inscrita na mente do homem, como queria Descartes. Há também a exclusão do ateu da sociedade. Para Locke a crença em Deus, embora não seja inata, é tão evidente no curso da natureza que não é possível rejeitá-la e, portanto, $o$ ateu também não deve ser tolerado. Santos (2014) também aponta problemas nessas concepções. ${ }^{7}$ No entanto, essas limitações do pensamento de Locke devem-se em parte ao fato de ele estar restrito a seu tempo e em parte, 
à sua intenção de propor uma solução prática e política para o problema dos conflitos religiosos. Se, por um lado, ele não se sai bem em suas construções teóricas mais abstratas, por outro, consegue estabelecer uma ampla argumentação no que diz respeito à tolerância. Suas ideias ganham força, pois se sustentam tanto na prática política, dado que é uma solução de aplicação viável, como também se sustentam nos princípios iluministas de liberdade e igualdade. A igreja de hoje não é mais o que fora em sua época, mas é preciso ressaltar aqui a atualidade do pensamento de Locke quando falamos da difícil relação entre o poder público e o poder eclesiástico. Locke continua sendo uma referência fundamental no debate desses temas.

\section{NOTAS}

${ }^{1}$ Aluno do Programa de pós-graduação em Filosofia da Universidade Federal de Sergipe e membro do Núcleo de Estudos em Filosofia da história e Modernidade (NEPHEN). E-mail: mykael.viana@gmail.com.

${ }^{2}$ Sobre os papistas e o contexto religioso inglês do século XVII ver Klibansky (1965)

${ }^{3} \mathrm{O}$ termo magistrado abrange em Locke, tanto o poder legislativo quanto o executivo. Ele afirma que é melhor para o Estado que tais poderes estejam em mãos diferentes. Essa é uma condição necessária 
para a construção de um bom Estado. Para um maior aprofundamento da distinção entre legislativo e executivo em Locke, ver Laslett (2005).

${ }^{4}$ Em matéria de política é muito difícil obter o consenso absoluto da comunidade. Locke reconhece essa dificuldade e afirma que no fim as decisões devem ser tomadas em consonância com a vontade da maioria. Ver Segundo Tratado (2005, p.469)

${ }^{5}$ As citações de Muller são referentes ao Ensaio (1973, p.137 e p.139)

6 Como teólogo, Locke também defende que a interpretação das Sagradas Escrituras pode ser feita por qualquer um, sem necessitar de intermediários. Isso fica claro em seu escrito Infalibilidade de 1662. (Ensaios Políticos, 2007, p.253-259).

${ }^{7}$ Sobre a recusa do ateísmo escreve Santos: se o próprio Locke propõe a separação das esferas e competências entre o Estado e a Igreja como forma de pôr fim aos conflitos religiosos, inexoravelmente a laicização seria a consequência mais evidente desse distanciamento entre as duas instituições, razão pela qual os ateus seriam a face mais proeminente deste novo cenário. (SANTOS, 2014, p.230).

\section{REFERÊNCIAS BIBLIOGRÁFICAS}

DUNN, J. Locke. São Paulo: Loyola, 2003.

KLIBANSKY, R. Prefácio. In: LOCKE, J. Carta Sobre a Tolerância. Portugal, Lisboa: Edições 70. 1965. pp. 13-35. 
GOUGH, J.W. A separação de poderes e soberania. In: QUIRINO, C. g.; DE SOUZA, M.(orgs.). O pensamento político clássico. Brasil, São Paulo: T.A. Queiroz, 1980. pp. 183-205.

LASLETT, P. A teoria social e política dos "Dois tratados sobre o governo". In: QUIRINO, C. g.; DE SOUZA, M.(orgs.). O pensamento político clássico. Brasil, São Paulo: T.A. Queiroz, 1980. pp. 183-205.

LASLETT, Peter. Introdução. In: LOCKE, John. Dois Tratados sobre o governo. São Paulo: Martins Fontes, 2005.

LOCKE, J. Carta acerca da tolerância. Lisboa: Edições 70, 1965.

LOCKE, J. Dois tratados sobre o governo. São Paulo: Martins Fontes, 2005.

LOCKE, J. Ensaio acerca do entendimento humano. São Paulo: Nova Cultural, 1973.

LOCKE, J. Ensaios Políticos. São Paulo: Martins Fontes, 2007. Organizado por Mark Goldie.

MULLER. F.M. Ideias inatas e suas consequências políticas. In: Kalagatos. Fortaleza, v.5 n.10, 2008. pp. 57-82.

SANTOS, A.C. O espírito do ateísmo em Locke. In: Filosofia Unisinos. São Leopoldo, 15(3): sep/dec 2014 . pp. 226-236. 